\title{
Dimensión social del tráfico ilícito de bienes culturales
}

Tania García

"Patrimonio es un activo valioso que transcurre del pasado al futuro relacionando a las distintas generaciones" (Ballart y Tresserras; 2001:12)

Creeríamos que el tráfico ilícito de bienes culturales (TIBC) solo afecta a bienes muebles e inmuebles, es decir, objetos cerámicos, pinturas, esculturas, grabados, monedas, libros, textiles, tumbas, sitios arqueológicos y coloniales; retablos, ruinas de fortificaciones, cementerios, edificaciones y monumentos. Sin embargo, este no es el problema central que enfrentamos. Nos referimos fundamentalmente a la pérdida de la memoria colectiva como consecuencia de la depredación de de los objetos simbólicos de pueblos y comunidades.

La cadena del TIBC está conformada por huaqueros, comerciantes de antigüedades, coleccionistas públicos y privados, casas de subastas, delincuentes comunes o bandas organizadas que facilitan la circulación de piezas provenientes de excavaciones ilegales, robos y venta de objetos de prohibida comercialización; esta cadena no siempre es identificada debido a intereses económicos, políticos, sociales y culturales como:

- Dinámica de una economía subterránea que invierte fortunas en bienes culturales patrimoniales.

- Un mercado global activo, que mueve enormes cifras en base a la oferta y la demanda en una aparente legalidad.

-La corrupción en la mayoría de los países que facilita el tránsito por fronteras terrestres, aéreas o marítimas a cambio de estipendios 
- Intereses de representatividad social y económica de ciertos “coleccionistas".

- Inequidades sociales, que señalan al huaquero como único responsable del comercio, tráfico y destrucción del patrimonio cultural .

- Modernas tecnologías que facilitan las transacciones con un menor riesgo $\mathrm{y}$ anonimato.

- Débil legislación en el ámbito penal.

- Falta de armonización en la legislación internacional.

- Incumplimiento de los Estados Parte.

- Falta de valoración y conocimiento de los recursos patrimoniales de pueblos y comunidades.

Para develar la complejidad del problema analizaremos tres aspectos. El primero relacionado con la cadena de involucrados; el segundo, relativo a la manera de "legalizar" la posesión de bienes culturales patrimoniales de procedencia dudosa, y el tercero corresponderá al análisis de las sociedades o entorno, que de una manera u otra pueden ser permisivas ante este tipo de delito.

El TIBC, comprende actividades de exportación, importación y transferencia ilícitas de bienes culturales patrimoniales, o no, establecidos en los marcos legales. A partir de la tipificación del delito, definida en la $17^{\mathrm{a}}$. Reunión de la Unesco, la adhesión de los Estados y sobre todo la implantación de los órganos administrativos con el respectivo cuerpo legal, es que podemos hablar de tráfico ilícito de bienes culturales.

Para definir o seleccionar los bienes que constituyen el patrimonio del Estado ecuatoriano, debemos necesariamente remitirnos, en nuestro caso, a la Ley de Patrimonio Cultural, Art. 7, literales de la a) hasta la j). Esta selección sin duda es arbitraria, puesto que en primer lugar tenemos un marco jurídico que delimita esa selección y, por otro lado, quienes los califican no están desprovistos de sus propias visiones. En este sentido, las categorías deben entenderse en un momento histórico y político determinado. En consecuencia, esta selección de patrimonio cultural obedece a un supuesto de orden social (Csikszentmihalyi, 1993: 28). 
Los bienes culturales materiales, a su vez, están constituidos por dos categorías: bienes muebles e inmuebles, es decir, responden a esta clasificación en la condición de movilidad o trasportación. Sin embargo, también esta clasificación es limitante, puesto que obedece tan solo a valores que se expresan materialmente; sin duda que se está superando esta concepción, y hoy se reconoce que todo objeto aparte de sus valores materiales tiene implícitamente valores o cualidades inmateriales, es decir, se reconoce la idea o el motivo que propició su creación, definida como patrimonio inmaterial (PCI). En consecuencia, la pérdida y depredación del patrimonio material implica también la pérdida del patrimonio inmaterial, es decir, usos, prácticas religiosas, rituales, festividades, vida cotidiana, etc.

\section{Cadena de involucrados en el TIBC. Huaqueros y coleccionistas}

La cadena de involucrados está conformada por una serie de actores que, de acuerdo con la ubicación en la pirámide social, pueden ser considerados delincuentes o personajes reconocidos y estimados. En el TIBC pueden intervenir huaqueros, comerciantes, coleccionistas, "profesionales", mafias organizadas, casas de subastas y compradores de buena fe.

Los bienes culturales más vulnerables históricamente han sido los provenientes de contextos arqueológicos terrestres y subacuáticos, ya que generalmente no se han identificado oficialmente, y pueden estar en cualquier sitio. El aparente "anonimato" ante las autoridades competentes los hace especialmente atractivos a huaqueros, buscadores de tesoros, traficantes de bienes culturales, o inescrupulosos profesionales que han hecho de esta actividad un comercio rentable a escala global. Para romper esta cadena de comercio ilegal, el International Council of Museums (Icom) publicó, en el 2002, la Lista Roja, que es una alerta documentada sobre el TIBC.

La Lista Roja nos proporciona algunos datos alarmantes del TIBC en América Latina. Estiman, por ejemplo, que un $80 \%$ de todos los sitios arqueológicos conocidos en la península de Yucatán. México han sido saqueados, que las figuras Nayarit-México provienen el 90\% de excavaciones ilegales —huaquerismo-. Con respecto al material cultural religioso, según la misma Lista Roja, el 10\% de las iglesias peruanas han sido saqueadas recientemente. Lamentablemente en esta lista también está Ecuador, con demanda de piezas de patrimonio cultural en mercados nacionales e internacionales. 
Al interior del territorio ecuatoriano se conoce de sitios destruidos por un huaquerismo intensivo en Cerro Narrí-Provincia Del Cañar hacia 1920 (BCE: 2010; 62) la zona del río Santiago en la Tolita- provincia de Esmeralda, hacia 1940; los cerros Jaboncillo, Verde, Guayabal y de Hojas, en la provincia de Manabí, despojados desde hace un siglo de sus contenidos culturales; el huaquerismo masivo producido en Alacao-Provincia de Riobamba, en el 2005 depredó contextos arqueológicos puruhá. En la década de los 80, Atacames-provincia de Esmeraldas vio perder su patrimonio arqueológico durante la ejecución de obras de infraestructura para la ciudad.

Por otro lado, el patrimonio paleontológico tampoco está a salvo. En el norte del país, el conocido valle de los Mastodontes, ubicado en la comunidad de Cuesaca del cantón Bolívar, es frecuentemente visitado por huaqueros que extraen los restos óseos para colocarlos en el mercado nacional a través de coleccionistas, casas de antigüedades o museos.

El cuadro que mostramos inmediatamente evidencia la riqueza patrimonial relativa a los sitios arqueológicos en Ecuador, por ende, la responsabilidad del Estado para ejercer la rectoría y la demanda en cuanto a necesidades de protección para evitar el saqueo y destrucción de la memoria prehispana e hispana contenida en los sitios arqueológicos.

\begin{tabular}{|c|c|c|c|}
\hline \multicolumn{2}{|c|}{$\begin{array}{l}\text { Sitios por } \\
\text { Periodos }\end{array}$} & $\begin{array}{l}\text { Número de } \\
\text { Yacimientos }\end{array}$ & $\%$ \\
\hline \multicolumn{2}{|c|}{ Paleontológico } & 108 & 2,0 \\
\hline \multirow{5}{*}{ 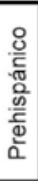 } & Paleoindio & 86 & 1,00 \\
\hline & Formativo & 84 & 1,00 \\
\hline & $\begin{array}{l}\text { Desarrollo } \\
\text { Regional } \\
\end{array}$ & 302 & 5,00 \\
\hline & Integración & 603 & 9,00 \\
\hline & Inca & 73 & 1,00 \\
\hline \multicolumn{2}{|c|}{ Colonial } & 26 & 0,4 \\
\hline \multicolumn{2}{|c|}{ Republicano } & 25 & 0,3 \\
\hline \multicolumn{2}{|c|}{ Sin información } & 5.275 & 81,0 \\
\hline & Total & 6.582 & 100 \\
\hline
\end{tabular}

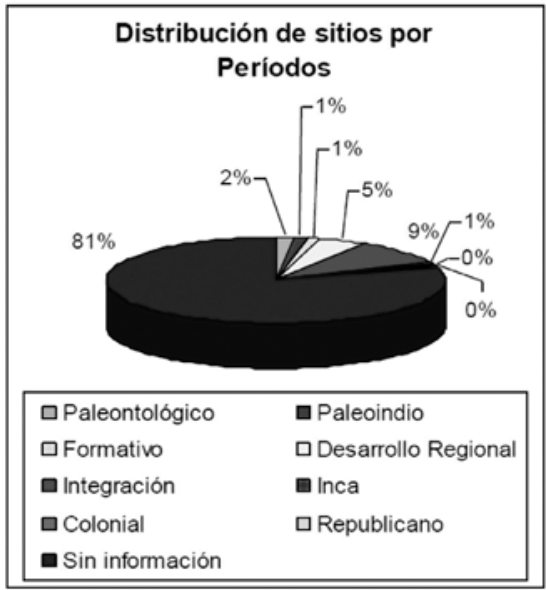

6.2.2 Sitios arqueológicos por filiación cultural.

Ecociencia, 2010. 
Otro aspecto importante en cuanto a la protección del patrimonio cultural frente al TIBC es el relativo al régimen de propiedad de las tierras. El cuadro siguiente nos ilustra el estado de la situación referente a este tema, pudiendo colegir que en teoría solo están debidamente protegidos el 12,84\% de los sitios que, según el régimen de propiedad, pertenecen al Estado.

\section{Régimen de tenencia de tierra y sitios arqueológicos}

\begin{tabular}{|l|c|r|}
\hline $\begin{array}{c}\text { Régimen } \\
\text { tenencia de } \\
\text { tierra }\end{array}$ & $\begin{array}{c}\text { Número de } \\
\text { Yacimientos }\end{array}$ & $\%$ \\
\hline Abandonado & 49 & 0,74 \\
\hline Público & 845 & 12,84 \\
\hline Privado & 3.500 & 53,18 \\
\hline Sin información & 2.188 & 33,24 \\
\hline Total & $\mathbf{6 . 5 8 2}$ & $\mathbf{1 0 0}$ \\
\hline
\end{tabular}

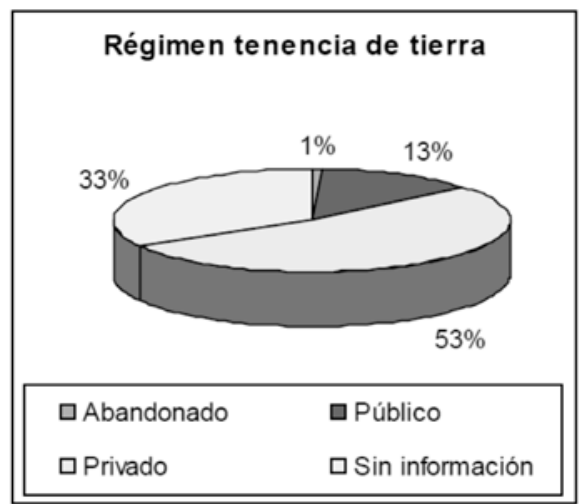

Elaboración: Ecociencia 2010.

Estos dos datos, el referente a la magnitud de la riqueza patrimonial y el régimen de propiedad de las tierras, no hacen más que corroborar que la protección del patrimonio cultural no es una tarea exclusivamente del Estado, puesto que materialmente es incapaz, por la magnitud a la que se enfrenta, de solucionar por sí mismo este problema. Por lo tanto, es importante el análisis de los involucrados en la cadena del TIBC y su responsabilidad.

Los primeros en la cadena de involucrados que participan en el TIBC, a quienes generalmente se los estigmatiza y se les asigna el peso de la ley con referencias históricas tan antiguas, son los huaqueros, y la actividad que desarrollan se conoce en Ecuador como huaquerismo. ${ }^{1}$ Dan cuenta de esta tres Reales Cédulas del período colonial americano: $1523,1538,1551$, que autorizaban el saqueo de

1 Actividad ilegal que actúa en contextos arqueológicos terrestres para obtener bienes culturales que luego los pone en circulación, a través de coleccionistas, casas de anticuarios y/o compradores de buena fe. 
tumbas y templos; al parecer esta práctica se extendió tanto que fueron necesarias posteriormente otras dos Cédulas Reales prohibiéndolas, la de octubre de 1549 y otra del 4 de septiembre de 1551 (Matos: 1979); ello, sin embargo, tendió no a proteger los testimonios del pasado prehispánico, sino a garantizar la captación de los tesoros para la Corona española.

El impacto del huaquerismo se devela cuando empezamos a indagar sobre estas prácticas; y una y otra vez nuestra historia se ve salpicada de hechos que llaman la atención por el volumen de material metálico; por la cantidad de colecciones privadas de inigualable riqueza cultural de bienes de prohibida comercialización existentes; por el número de bienes culturales que forman parte de estas colecciones y por el número de colecciones reportadas e identificadas fuera del territorio nacional. Pero lo alarmante de estos datos es que con seguridad, ninguna de estas colecciones provienen de investigaciones científicas.

Sin embargo, la historia de los coleccionistas ${ }^{2}$ es muy distinta a la de los huaqueros. Aquella actividad ha gozado siempre de muy buena reputación, y quienes asumen esta práctica gozan de consideración y estima, como lo constatamos hasta la actualidad; esta dicotomía, en la relación de la cadena de involucrados, es la que nos interesa analizar, puesto que las actividades de los dos personajes están íntimamente relacionados. El primero como proveedor de bienes- mercancía y el segundo como consumidor de productos culturales de profunda significación económica y social; los dos en estrecha relación, debido a que actúan en la oferta y demanda de bienes culturales de prohibida comercialización.

Constatamos los resultados de una actividad no científica a través del análisis de colecciones legalmente registradas en el departamento de Inventario del Instituto Nacional de Patrimonio Cultural. Las 13.773 piezas arqueológicas pertenecientes a colecciones privadas registradas únicamente en Quito, hasta el año 2009, no provienen de investigaciones científicas. Por lo tanto, es de inferir que fueron adquiridas a comerciantes de bienes culturales, entre los cuales seguramente estuvieron presentes los huaqueros.

\footnotetext{
2 No nos referimos al coleccionismo en general. El coleccionismo que despierta sospechas es aquel relacionado fundamentalmente con la adquisición de bienes culturales arqueológicos, puesto que en estricto sentido según la Ley de Patrimonio Cultura Ecuatoriano no se justifica de ninguna manera la posesión de estos bienes en manos privadas.
} 


\section{Colecciones arqueológicas registradas por el INPC \\ Región 1 Quito \\ (Datos consignados hasta marzo 2010)}

\begin{tabular}{|c|c|c|c|c|c|}
\hline Región & $\begin{array}{c}\text { \# Registros } \\
\text { Totales }\end{array}$ & $\begin{array}{c}\text { Colecciones } \\
\text { arqueológicas }\end{array}$ & $\begin{array}{c}\text { Número de } \\
\text { Bienes } \\
\text { culturales } \\
\text { arqueológicos }\end{array}$ & $\begin{array}{c}\text { Total de } \\
\text { bienes } \\
\text { culturales }\end{array}$ & $\%$ \\
\hline $\begin{array}{c}\text { Centro } \\
\text { Norte } \\
\text { (Sierra) }\end{array}$ & 812 & 219 & 13.773 & 17.928 & 76.82 \\
\hline
\end{tabular}

Sobre el "coleccionismo" debemos preguntarnos ¿por qué mira la sociedad este hecho de distinto modo al del huaquerismo? Pero, sobre todo, ¿se justifica aún la práctica de coleccionismo que incita la destrucción de los contextos arqueológicos y coloniales en el siglo XXI?

Estos datos nos permiten ahora intentar esbozar el fenómeno del coleccionismo, enfocándonos en las consecuencias de esta actividad en el siglo XXI, y la discusión en torno a ella.

Existen dos corrientes bien diferenciadas respecto al coleccionismo:

1. La corriente que pregona que la actividad del coleccionista suple al Estado, quién es incapaz de realizar el manejo del patrimonio cultural. Esta corriente es liberal, condescendiente y se inserta plenamente con el mercado. Generalmente pregonan estos beneficios los propietarios de los museos particulares y coleccionistas activos, como no podía ser de otra manera.

2. Una segunda corriente considera al coleccionismo de bienes culturales de prohibida circulación como un eslabón del TIBC, por lo tanto debe ser detenida. Esta corriente es la más dura y no admite mediaciones, reconoce el proceso del coleccionismo en determinado momento de la historia, pero es enfática en señalar que esta es nociva y en la actualidad carece de sentido y es contraria a las disciplinas científicas. Por ejemplo, Ricardo Elia, arqueólogo italiano, ha señalado que el verdadero huaquero es el coleccionista.

Esta segunda posición es la que por fuerza de la razón va cobrando primacía en los ámbitos científicos, puesto que es insostenible la posición anterior en la actualidad. Por ejemplo, existen códigos deontológicos que se van difundiendo 
sobre el uso de material arqueológico proveniente del huaquerismo y de colecciones sin contexto; algunos países no exhiben en los museos antropológicos nacionales colecciones que provienen de compras a terceros, de TIBC y huaquerismo; y revistas especializadas no permiten publicaciones científicas que tomen como ejemplo piezas sin contexto (Salazar, 2007).

\section{Blanqueo de bienes}

El segundo aspecto que creemos importante analizar es la forma en que los coleccionistas de bienes culturales de prohibida comercialización actúan para afirmar la posesión de bienes culturales y de alguna manera legalizar su posesión. A esta puesta en dominio público se denomina blanqueo de bienes. Aquí las preguntas claves son: ¿Desde cuándo podemos hablar de blanqueo?, y, consecuentemente ¿por qué no se sanciona esta práctica? Estas dos preguntas constituyen el termómetro para analizar y medir a la sociedad.

El blanqueo de bienes culturales es una práctica común, generalmente de coleccionistas de bienes culturales de prohibida circulación, que consiste en exponerlos o presentarlos al público a través de muestras, exposiciones e incluso abriendo museos. Este artificio de promoción y difusión público permite que la sociedad asuma y conozca su existencia, pero sobre todo aparentemente "legaliza" la propiedad de los bienes, que según la Ley de Patrimonio Cultural de Ecuador son de propiedad única del Estado.

El caso emblemático de blanqueo de bienes culturales para buena parte de América Latina muestra del saqueo a gran escala, de alto impacto, que ha involucrado a distintas personalidades, es el caso Patterson.

Leonardo Patterson, costarricense alemán, recorrió buena parte de América Latina, adquiriendo bienes culturales patrimoniales y pretendió vender parte de "su" inigualable colección en España a través de una exposición exquisita, cuyos titulares involucraron a personalidades de reconocida trayectoria mundial que lo alabaron en su momento.

El problema salió a la luz debido a la existencia probada en aquella colección de bienes culturales patrimoniales reportados como robados en el territorio peruano; en esta colección además se identificaron bienes culturales mexicanos, guatemaltecos, costarricenses, ecuatorianos y colombianos. A raíz de la exposición y publicación del respectivo catálogo, los países involucrados 
conocieron la magnitud de la depredación, por ello iniciaron procesos de reclamo en las cortes españolas y alemanas, enviaron peritos y movilizaron esfuerzos para enfrentar este caso en las cortes internacionales.

El caso Patterson es uno de los tantos esfuerzos de intento de blanqueo de colecciones patrimoniales de prohibida circulación. Sin embargo, creemos que en Ecuador la situación continúa inalterada como hasta en el siglo XIX respecto al coleccionismo, puesto que no hemos dado un paso adelante al hacer el seguimiento sobre la procedencia de los bienes culturales arqueológicos que conforman las colecciones de personas naturales y jurídicas, y permanentemente asistimos a inauguraciones, exposiciones, aperturas de museos y registro de colecciones que exhiben bienes culturales patrimoniales de prohibida circulación, según la Ley.

La puesta en escena pública, o blanqueo de bienes culturales, se logra puesto que la sociedad "reconoce" la tenencia de estos bienes culturales, y de alguna manera se oficializa la posesión.

La tabla inferior es el análisis de una muestra representativa de los museos que se promocionan en la web en Ecuador, y la difusión que se hace con respecto a las colecciones que administran; queda claro otra vez el número de museos que administran bienes de "prohibida circulación" según la Ley de Patrimonio Cultural, y el proceso de blanqueo del patrimonio cultural a través de esta puesta en escena y atención al público a través de los museos.

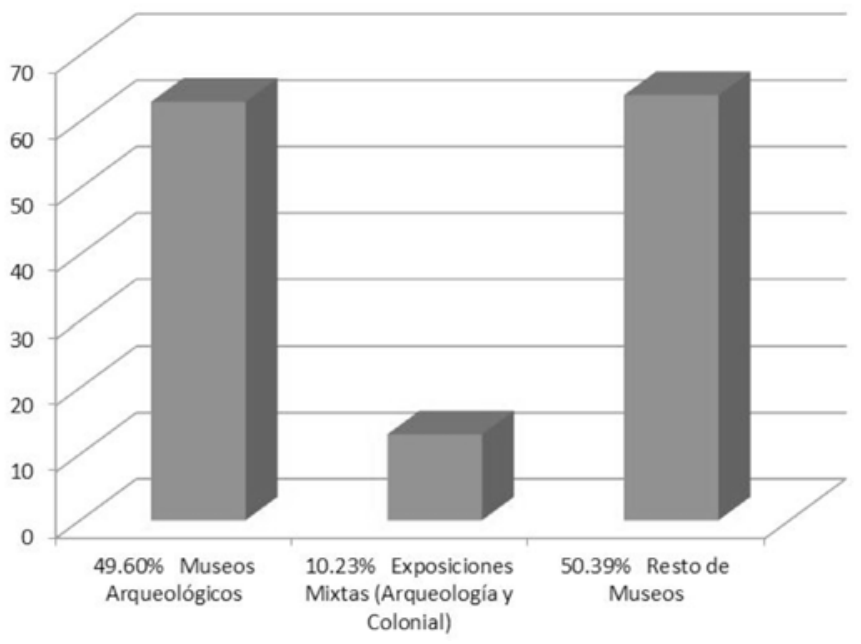

Elaboración propia 
Estas tablas son apenas referenciales, puesto que hasta ahora existe mucha resistencia para registrar las colecciones, a pesar de que el Estado ha demostrado que no tiene interés en realizar confiscaciones. Estos datos son en consecuencia la punta del iceberg. Atreviéndonos a hacer un cálculo optimista, diremos que constituye un $50 \%$ de lo que falta por inventariar.

La actividad intensiva de los huaqueros en los países, y la gran cantidad de bienes culturales que ha salido, ha motivado a que algunos estudiosos propongan una clasificación: "Países exportadores" "Países de tránsito", "Países importadores”. Por países exportadores: Suramérica, África, Oceanía y Kampuchea, y otros ya despojados casi por completo (Nauru) (Prott y O’keefe: 1983; 1)

Países de tránsito: Gran Bretaña, Francia, República Federal de Alemania, Suiza y los Estados Unidos, y algunos Estados de América del Sur, África y Australia, tratándose en todos los casos de piezas provenientes de países vecinos. Por países importadores denominan a los Estados donde se encuentran los principales coleccionistas: América del Norte y Europa. Por otro lado, identifican a otros países importadores que "requieren" bienes de origen europeo, como ciertos países de América del Sur, Sudáfrica, Australia, Canadá y Nueva Zelanda (Prott y O’Keefe: 1983; 1).

Sin embargo, de esta denominación y aparentes precisiones no creemos que sea exacta. Es importante dar el nombre que le corresponde a las actividades ilegales. Por lo tanto, lo justo sería hablar de países depredados o países expoliados; y países permisivos ante el TIBC, tanto para los que facilitan la circulación cuanto para los que son el destino de este mercado ilegal. Creemos que cuando se dé una denominación apropiada, sin falsas etiquetas, estaremos en condición de hablar de un cambio de actitud en la sociedad en los ámbitos nacional e internacional. Por ende, habremos también dado un paso adelante en la lucha contra el TIBC a escala internacional.

Los países expoliados a los que los autores Prott y O’Keefe se refieren son los nuestros, de Centro y Suramérica, de África, Oceanía y Asia; poseedores de enormes riquezas materiales e inmateriales que son codiciados por coleccionistas de occidente, preferentemente de Norteamérica y Europa, quienes actúan gracias a que existe una cadena de involucrados que les provee de los materiales culturales muchas veces adquiridos bajo pedido. Por ello es que insistimos que el estigmatizar tan solo a los huaqueros y aplaudir a los coleccionistas es 
una práctica desequilibrada, en la que la aplicación de la justicia es inequitativa, por lo tanto, atentatoria a los derechos humanos; que esta dicotomía incentiva el TIBC; en consecuencia, es un componente más de la inseguridad ciudadana y de la inseguridad global.

\section{Seguridad ciudadana y tráfico ilícito de bienes culturales}

El tercer aspecto que anunciábamos pretende analizar a la sociedad o entorno, que creemos puede actuar permisivamente o no frente al TIBC. Los actores de la cadena del tráfico ilícito, tienen un papel específico y están íntimamente relacionados entre sí. Por lo tanto, también deberían ser responsables de igual manera frente a un hecho delictivo; es esta la razón por la que hablamos de cadena de involucrados para demostrar que cada eslabón se relaciona y cumple una función al facilitar la circulación de piezas provenientes de excavaciones ilegales, hurtos, robos, y colocarlas en el mercado legal e ilegal.

Creemos que la razón por la que un amplio espectro de la sociedad reacciona con una doble moral frente al TIBC se debe a los intereses que entran en juego y otros problemas estructurales. Por tanto, es importante develar las causas, escenarios y aspectos que atraviesa el problema del TIBC para provocar un cambio interno que desincentive la adquisición de bienes de prohibida circulación.

Un artículo de Rubén Bravo en un diario nacional ecuatoriano habla sobre este tema, y se refiere a la necesidad de la aplicación de políticas públicas que garanticen la igualdad; que al no existir igualdad en la aplicación de las leyes y justicia para todos, la problemática general alienta y alimenta la inseguridad ciudadana; por ende, son escenarios propicios para el TIBC.

Algunas líneas del problema respecto a por que la sociedad es permisiva con casi todos los actores que intervienen en el TIBC las exponemos a continuación para analizar su complejidad.

Por un lado, el "robo", "la depredación del patrimonio de todos", el "saqueo", "el expolio de provincias y países enteros" por individuos de una condición económica determinada se justifica como una forma de vida. Si parafraseamos este justificativo, también se aceptaría que las otras modalidades del crimen y la delincuencia común constituyen un modo de vida. Por lo tanto, el modo 
de vida denominado huaquerismo, ejercida generalmente por personas de escasos recursos económicos, debe ser detenido. La condición de pobreza para delinquir no es de ninguna manera un justificativo para depredar el patrimonio cultural.

Sin embargo, la explicación de esta práctica debido a la pobreza, a la falta de educación y al desconocimiento de las leyes, parecería ser no tan cierta. El huaquero en la actualidad actúa a la sombra, trabaja bajo pedido con clientes conocidos, no se expone, pone en circulación los bienes culturales de acuerdo con el mercado y al momento de negociar sabe cómo llegar al precio; esta actitud demuestra que conocen la ilegalidad que cometen.

Es realmente impactante escuchar a poblaciones que habitan en sitios arqueológicos desconocer los valores culturales de los pueblos anteriormente asentados en aquellos territorios; en muchas ocasiones tampoco se reconocen como sus descendientes. De ahí que pueden participar en la destrucción de tumbas para obtener los ajuares funerarios, desmantelar construcciones para reciclar los materiales y destruir los contextos arqueológicos para evitar que las autoridades intervengan.

Esto nos lleva a un segundo punto, que es la falta de trabajo de los órganos competentes para mostrar experiencias exitosas de otras comunidades que aprovecharon estos recursos patrimoniales y mejoraron sus condiciones, como las comunas de Agua Blanca y Salango, en la provincia de ManabíEcuador, entre otras.

Otro aspecto que se debe tratar es la relación del TIBC y la seguridad ciudadana; es en el que menos énfasis se ha puesto. Cuando se habla de patrimonio y bienes culturales se comentan como hechos anecdóticos, la violencia asociada a este tipo de robo no causa mayor interés entre las autoridades, puesto que generalmente están concentradas en "otros" problemas más acuciantes de la sociedad como el sicariato, los accidentes masivos en carreteras y la inseguridad ciudadana en los espacios públicos. Generalmente la pérdida de bienes culturales es asociada al robo común de otros bienes que "aparentemente tienen mayor valor". La falta de documentos que sustentan las indagaciones, como son los inventarios de bienes culturales patrimoniales, hace que el problema se invisibilice en torno a la delincuencia común. 
Finalmente, diremos que la inseguridad no se combate con el amurallamiento de las viviendas; tiene relación directa con los desequilibrios sociales, que es precisamente el problema al que hemos aludido en el TIBC.

La ciudadanización del patrimonio comprende otras dimensiones. En ese contexto, esta actividad tendrá importancia cuando entendamos que el problema del TIBC afecta a la seguridad ciudadana, al orden económico, a la memoria colectiva y a los derechos culturales. Por lo tanto, la lucha contra el TIBC no es solo una guerra para la recuperación de bienes materiales, trata sobre aspectos trascendentes que aglutinan y dan sentido a pueblos y comunidades.

\section{Referentes bibliográficos}

Arango Cano, Luis. Recuerdos de la guaquería en el Quindío; Bogotá; Editorial de Cromos - Luis Tamayo y Co. 1924.

Ballart Josep; El patrimonio histórico y arqueológico: valor y uso; 2da. edición; Ariel Patrimonio; Barcelona - España; julio 2002.

Centro Colombo Americano Medellín; Protegiendo el patrimonio cultural contra el saqueo y tráfico ilícito; Departamento de Estado de los Estados Unidos de América, OEA, Embajada de los EEUU en Bogotá, Ministerio de Cultura; Medellín, Colombia 2008.

Ciskszentmihalyi, M. Why We Need Things, en S. Lubar y W. D. Kingery (eds), Washington y Londres, Smithsonian Institution Press, 1993.

INTERNATIONAL COUNCIL OF MUSEUMS (ICOM), Lista Roja, Bienes Culturales latinoamericanos en peligro, publicación 2002.

H. CONGRESO NACIONAL, COMISIÓN DE LEGISLACIÓN Y CODIFICACIÓN; Ley de Patrimonio Cultural, Codificación 27, Registro Oficial 465 del 19 de noviembre del 2004.

Osvaldo Hurtado Larrea, Presidente Constitucional de la República; "Reglamento a la Ley de Patrimonio Cultural"; Decreto Ejecutivo 2733, Registro Oficial 787 de 16 de julio de 1984.

MINISTERIO COORDINADOR DE PATRIMONIO, “Decreto de Emergencia del Patrimonio Cultural”; Primera Fase; Imprenta Sobocgrafic; Quito 2010.

Salazar, Ernesto; Revista Electrónica: Arqueología Ecuatoriana; "Los artefactos huaqueados en la investigación científica"; http://www.arqueo-ecuatoriana. ec/es/deontologia/19-generalidades/57-los-artefactos-huaqueados-en-la-investig- 
acion-cientifica; martes, 20 de marzo de 2007; http://www.arqueo-ecuatoriana.ec/es/ deontologia/19-generalidades/57-los-artefactos-huaqueados-en-la-investigacioncientifica.

Bienes culturales: su tráfico ilícito y su restitución; Acción normativa http://portal. unesco.org/culture/es/ev.php-URL_ID=35252\&URL_DO=DO_TOPIC\&URL_SEC$\mathrm{TION}=201 . h t m l$.

Bisquert Cebrián, Carlos; "Interpol y su trabajo en relación con la protección del Patrimonio"; Oficina Central Nacional; INTERPOL España; http://www.mcu.es/patrimonio/docs/ MC/LCTI/LCTI_8_Interpol.pdf.

Lista Roja de bienes culturales latinoamericanos en peligro; EL SAQUEO DEL PATRIMOMIO LATINOAMERICANO; http://icom.museum/redlist . 


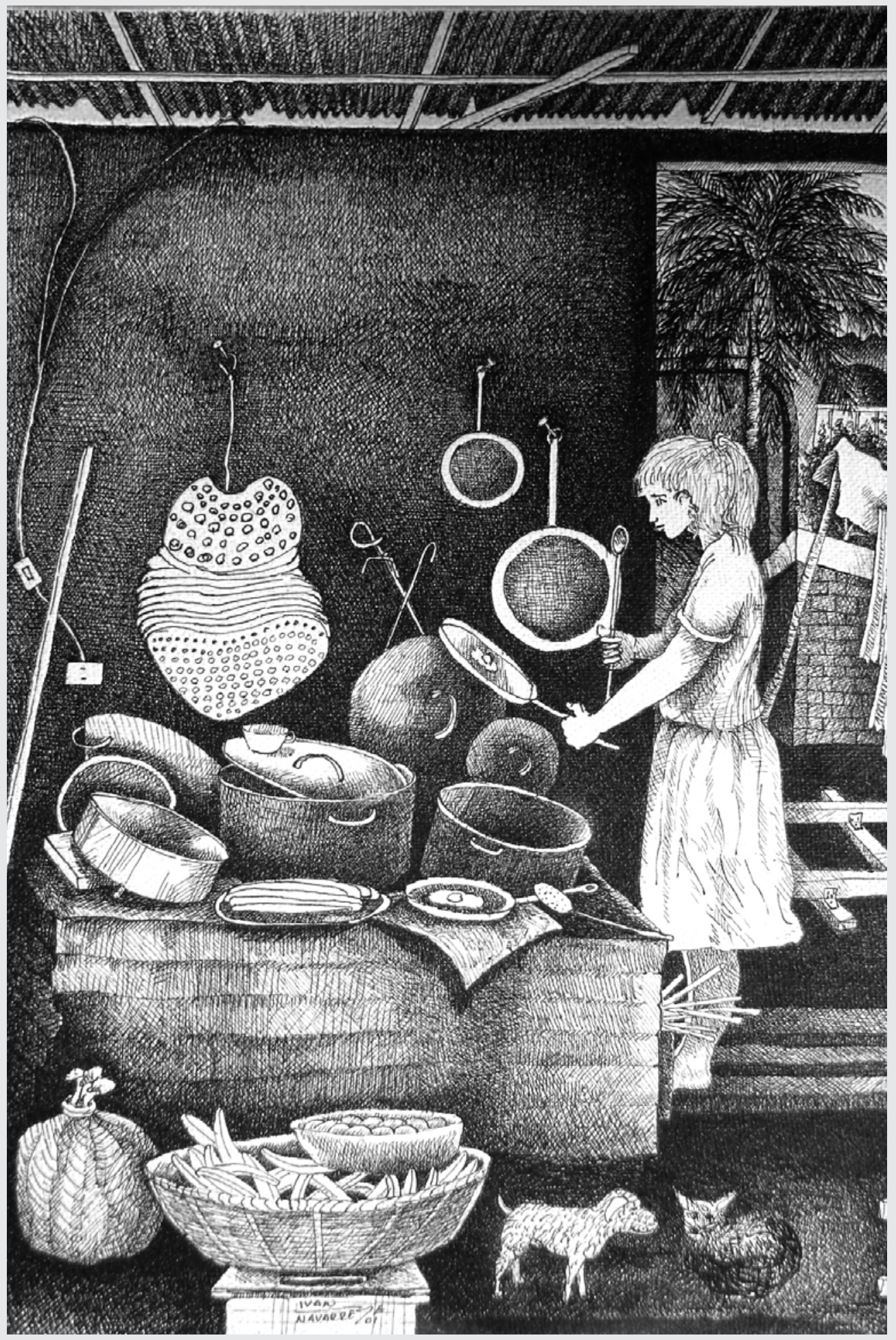

